\title{
Advanced basal cell carcinomas of the face: A Moroccan series
}

\section{Sara Elloudi, Aida Oulehri, HananeBaybay, ZakiaDouhi, Fatima Zahra Mernissi}

\author{
Dermatology Department of the University Hospital Center Hassan II, Fez, Morocco
}

Corresponding author: Sara Elloudi, MD, E-mail: dr.elloudi@gmail.com

\begin{abstract}
Background: Basal cell carcinoma (BCC) is the most common cutaneous skin malignancy. $85 \%$ of BCCs affect the face, a region particularly rich in noble organs. Although BCC progresses slowly, considerable local destruction and mutilation may be observed. Material and Methods: We performed a retrospective review of the database stored by our institution. All patients with histologically confirmed mutilating basal cell carcinoma of the face hospitalized at the dermatology department of the university hospital in Fez, Morocco, from 2015 through 2020 were evaluated. Results: Nine patients were included, with the tumors located in the lips, temporal region, orbital region, and cheeks, with sizes varying from 5 to $1 \mathrm{~cm}$. Conclusion: In the series, we were able to highlight the high-risk character of the subpopulation living in rural areas and the role of smoking as a major risk factor.
\end{abstract}

Key words: Basal cell carcinoma; Locally advanced; Face; Dermoscopy

\section{INTRODUCTION}

Basal cell carcinoma (BCC) is the most common form of human cancer [1]. BCC affects mainly sun-exposed areas and, in around $80 \%$ of cases, it appears on the head [2]. The main etiological factor responsible for $\mathrm{BCC}$ is chronic UV exposure and its pathogenesis is linked to the interplay between environmental and patient-dependent characteristics [3]. With the increase in the incidence of $\mathrm{BCC}$, and despite relatively low mortality, morbidity and treatment-related costs represent a significant burden to the health care system. Treatment options include medical and surgical modalities. The first therapy of choice is generally surgical excision with safe surgical margins [4]. Tumors of BCC exhibit a slow progression and metastases are found in only $0.5 \%$ of cases, but may result in considerable local destruction and disfigurement if treatment is neglected or inadequate [2]. In our study, we observed a series of nine cases with advanced BCC of the face. The aim is to describe the epidemiological, clinical, and histopathological features of this aggressive subtype of BCC and to evaluate its risk factors.

\section{Patients and Methods}

We performed a retrospective review of the database stored by our institution, with a wide acceptance of patients from the city of Fes and surrounding cities. All patients between January 2015 and September 2020 with advanced $\mathrm{BCC}$ of the face were evaluated.

The inclusion criteria were individuals over eighteen years of age with a BCC confirmed histologically, with the starting point and extension on the face and described as giant, which is defined according to the literature as a size greater than $5 \mathrm{~cm} \mathrm{[5]} \mathrm{and} \mathrm{aggressive,}$ which is defined as an infiltrating and destructive tumor of soft tissues and the noble organs of the face [6].

We excluded from our work BCC in genodermatosis, mainly xeroderma pigmentosum, in order to be able to highlight the risk factors of this severe form independently of other particular cases.

The data collected included the patient's age, sex, household, profession, occupation, sun exposure,

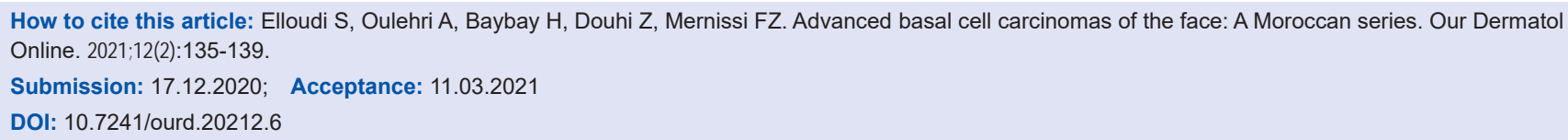


history of irradiation, and known risk factors for BCC. For each patient, we also calculated the interval between the appearance of the lesion and the consultation to look for potential reasons for the delay.

Clinical examination allowed us to characterize the patient's phototype and the tumor's site, size, semiological description, and dermoscopic characteristics. We also collected data on the histological subtype, the patient's management, and the follow-up.

\section{Ethics Statement}

Ethical approval was obtained from the ethics committees at Hospital Center University Hassan II in Fez, Morocco. All the patients were informed of the conditions related to the study and gave their written informed consent for the study and for publication.

\section{RESULTS}

Nine patients were hospitalized at our department during the established period. The sex ratio (F:M) was 1.25: five females and four males. The patients' age ranged from 61 to 110 years, with an average age of 78.55 years. All patients were from rural areas. Three out of the four males $(75 \%)$ were farmers; the fourth was a truck driver. All females worked in the fields. All patients were exposed to strong sunlight and never applied sunscreen. The only method of photoprotection was clothing: straw hats for males and covering clothes for females, who never wore hats.

Only one patient reported trauma prior to the development of the tumor in the temporal area. All males were smokers, with the number of cigarettes smoked per day varying between 10 and 30, with an average of 16.8, and with the duration of the smoking habit varying between 27 and 50 years, with an average of 36.75 years. $22.2 \%(2 / 9)$ of the patients were hypertensive and $11.1 \%$ (1/9) were diabetics. All patients recalled the beginning of the condition as a small lesion that gradually increased in size: as an erosion (55.6\%), a papule $(33.3 \%)$, or a nodule (11.1). The time between the appearance of the lesion and the consultation varied between 2 and 14 years, with an average of 5.4 years. The reasons found for this delay were a precarious social situation, a lack of financial means, remoteness of health services, and sometimes the asymptomatic character of recent lesions. Indeed, the majority of the patients consulted for pain, bleeding, or extension to a noble organ such as the eye or nose.

$88.9 \%$ of the patients had phototype III according to the Fitzpatrick scale. Two tumors were located on the lips, with complete destruction of the lip and extension to the mucous membrane; two were in the temporal region; three were in the orbital region, two of which led to complete destruction of the orbit; and one had a deep cheek tumor. The size of the tumors varied between 5 and $11 \mathrm{~cm}$, with an average of 6.7 $\mathrm{cm}$. All BCCs were ulcerative budding tumors with pearly borders (Fig. 1) and only one case was clinically pigmented (Fig. 2).

In all cases, dermoscopy revealed polymorphic vascularization composed of irregular linear vessels and tree-trunk vessels, with grey-blue ovoid nests on the periphery of the tumor in $88.9 \%$ of the cases (Fig. 3).

No patient had locoregional adenopathies or distant metastases. All patients initially benefited from a biopsy, which confirmed the diagnosis of BCC. All patients exhibited an infiltrative histological subtype, which was associated in $66.7 \%$ of cases with a nodular contingent and in $11.1 \%$ with an adenoid contingent.

All patients' treatment records were discussed in multidisciplinary oncodermatology meetings attended by dermatologists, oncologists, radiotherapists, and surgeons.

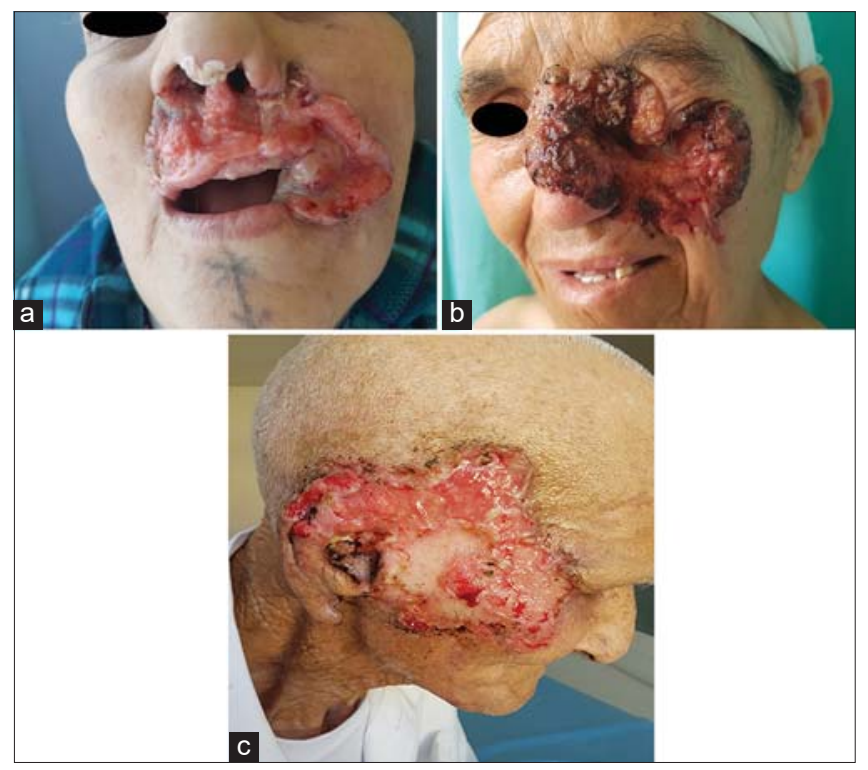

Figure 1: Locally advanced basal cell carcinoma with the destruction of (a) the nasal septum and the upper lip, (b) the orbital region, and (c) the temporal region and the auricle. 


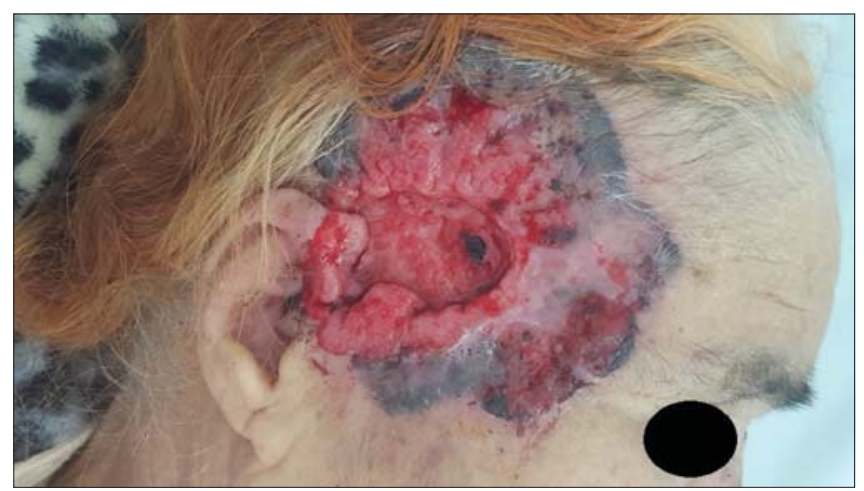

Figure 2: Pigmented locally advanced basal cell carcinoma of the temporal region and auricle.

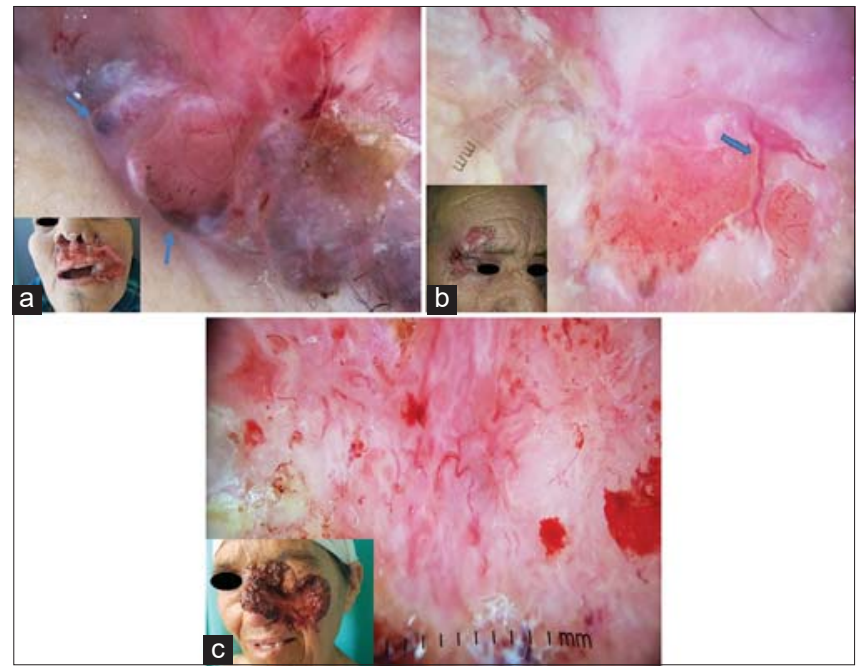

Figure 3: (a) Erythematous background, polymorphic vascularization, and blue-gray ovoid nests (blue arrows). (b) Erythematous background, polymorphic vascularization, and tree-trunk vessels (blue arrow). (c) Erythematous background, polymorphic vascularization, and shiny white structures.

Surgical management was indicated in eight patients and radiotherapy in one. Six patients underwent surgical excision with subsequent reconstruction. One patient died before any treatment (radiotherapy). One patient was lost to follow-up. During the follow-up period, we noted only one recurrence after a period of one year.

\section{DISCUSSION}

BCC most frequently occurs in the elderly [7] and is more common in males than females, with a male-tofemale ratio of approx. 2:1 [8]. In our study sample, we noted a very advanced age on average, but the female sex was slightly predominant. Given the primary role of early and long-term sun exposure in BCC, outdoor workers, particularly farmers, are at much greater risk of developing BCC [9]. In addition, the data demonstrates that farmers develop the disease at a younger age and are more likely to suffer from a recurrence [10]. We were also surprised to see that all our patients came from rural communities and were almost exclusively farmers, which adds to the results from the literature on the increased risk of severe forms in this high-risk population. It is clear, however, that more targeted programs are needed for high-risk groups, such as farmers. Sun exposure was also the main risk factor in our study sample, in addition to fair skin and smoking in males. If lesions of BCC are left untreated for years, they become progressively locally advanced [7]. Our study confirms this data since all our patients' consultations were significantly deferred in time; however, metastases were not found in any patient.

In the process of research, we realized that there was no consensus on the denomination and criteria that would define aggressive and destructive cases of BCC. The different names found in the literature are terebrant, giant, aggressive, and advanced.

Although not clearly defined, the word advanced usually implies that 1) there is a long history of treatment avoidance or repeated failed treatments and recurrences, 2) there is extensive tissue destruction in the surrounding anatomical area, and 3) it has become difficult or impossible to cure the tumor through standard surgery procedures (unresectable) or radiotherapy $[7,11]$.

The histological subtypes of BCC classified according to the risk of recurrence described by the current WHO classification [12] are 1) nodular, superficial, pigmented, infundibulocystic, and fibroepithelial (all low-risk) and 2) basosquamous or metatypical, sclerosing or morphoeic, infiltrating trabecular or micronodular, mixed-type, and with sarcomatoid differentiation (all high-risk). The adenoid type is a histological variant of BCC considered a subtype of the nodular subtype $[13,14]$. In our study, despite the presence of all clinical criteria of aggressiveness, we found no other high-risk histological types apart from the infiltrative type.

Peris et al. consider a more pragmatic and operational classification of BCC into easy-to-treat BCC, which involves the most common cases of $\mathrm{BCC}$, and difficultto-treat BCC [7].

There are two systemic medications, vismodegib and sonidegib, with a documented efficacy in locally advanced BCC (laBCC) [15]. Management should be 
carefully planned by a skin cancer multidisciplinary team $[16,17]$.

Chemotherapy may be considered for laBCC as the second- or third-line treatment in unresponsive patients or those who have progressed after vismodegib or sonidegib, often in combination with radiotherapy.

Radiotherapy may be considered the primary treatment if curative surgery is not possible or might be disfiguring or burdened by a poor aesthetic outcome, including BCCs located on the face (i.e., the eyelids, nose, lips) or large lesions on the ear, forehead, and scalp [18-20].

\section{CONCLUSION}

In this series, we wished to expose the dramatic aesthetic and functional repercussions of $\mathrm{BCC}$ of the face if treatment is delayed.

In addition to the known risk factors found in our patients, such as excessive sun exposure and a fair phototype, we were also able to highlight the high-risk character of the subpopulation living in rural areas, which is associated with excessive sun exposure, the absence of photoprotection measures, a precarious social situation, a lack of financial means, and sometimes the unavailability of health services. This implies that special and targeted attention must be directed toward this population.

Contrary to the literature, we were able to observe, in our series, that this serious form of BCC did not predominate among males but slightly among females. We were also able to highlight the detrimental role of smoking, found as a major risk factor in our series, which has rarely been described in the literature in this context.

The histological subtypes classified as aggressive were not found in our patients except for the infiltrative type.

Finally, despite the discussion of all our cases in a multidisciplinary oncodermatology team, the therapeutic options for these advanced forms were limited in the absence of targeted therapy (vismodegib or sonidegib) and immunotherapy (anti-PD-1). Our study emphasizes that these cases are not rare and that the introduction of such therapies would be beneficial for our population.

\section{Statement of Human and Animal Rights}

All the procedures followed were in accordance with the ethical standards of the responsible committee on human experimentation (institutional and national) and with the 2008 revision of the Declaration of Helsinki of 1975.

\section{Statement of Informed Consent}

Informed consent for participation in this study was obtained from all patients.

\section{REFERENCES}

1. Work Group; Invited Reviewers, Kim JYS, Kozlow JH, Mittal B, Moyer J, Olencki T, et al. Guidelines of care for the management of basal cell carcinoma. J Am Acad Dermatol. 2018;78:540-59.

2. Dourmishev L, Rusinova D, Botev I. Clinical variants, stages, and management of basal cell carcinoma. Indian Dermatol Online J. 2013;4:12-7.

3. Kim DP, Kus KJB, Ruiz E. Basal cell carcinoma review. Hematol Oncol Clin North Am. 2019;33:13-24.

4. Demirseren DD, Ceran C, Aksam B, Demirseren ME, Metin A. Basal cell carcinoma of the head and neck region: A retrospective analysis of completely excised 331 cases. J Skin Cancer. 2014;2014: 1-6.

5. Archontaki M, Stavrianos SD, Korkolis DP, Arnogiannaki N, Vassiliadis V, Liapakis IE, et al. Giant basal cell carcinoma: Clinicopathological analysis of 51 cases and review of the literature. Anticancer Res. 2009;29:2655-63.

6. Walling HW, Fosko SW, Geraminejad PA, Whitaker DC, Arpey CJ. Aggressive basal cell carcinoma: Presentation, pathogenesis, and management. Cancer Metastasis Rev. 2004;23:389-402.

7. Peris K, Fargnoli MC, Garbe C, Kaufmann R, Bastholt L, Seguin NB, et al. Diagnosis and treatment of basal cell carcinoma: European consensus-based interdisciplinary guidelines. Eur J Cancer. 2019;118:10-34.

8. Asgari MM, Moffet HH, Ray GT, Quesenberry CP. Trends in basal cell carcinoma incidence and identification of high-risk subgroups, 1998-2012. JAMA Dermatol. 2015;151:976-81.

9. Osmola-Mańkowska A, Silny W, Dańczak-Pazdrowska A, OlekHrab K, Mańkowski B, Osmola K, et al. The sun-our friend or foe? Ann Agric Environ Med. 2012;19:805-9.

10. Szewczyk M, Pazdrowski J, Golusiński P, Dańczak-Pazdrowska A, Łuczewski $Ł$, Marszałek S, et al. Basal cell carcinoma in farmers: An occupation group at high risk. Int Arch Occup Environ Health. 2016;89:497-501.

11. Morgan FC, Ruiz ES, Karia PS, Besaw RJ, Neel VA, Schmults CD. Factors predictive of recurrence, metastasis, and death from primary basal cell carcinoma $2 \mathrm{~cm}$ or larger in diameter. J Am Acad Dermatol. 2020;83:832-8.

12. DE E, D M, RA S, R W. WHO Classification of skin tumours. Accessed November 7, 2020. https://publications.iarc.fr/BookAnd-Report-Series/Who-Classification-Of-Tumours/WHOClassification-Of-Skin-Tumours-2018

13. Agarwal A, Raja A, Mahalingam S, Murhekar K. Multiple adenoid basal cell carcinoma: An uncommon presentation. Indian J Dermatol Venereol Leprol. 2019;85:393-6.

14. Amici JM, Dousset L, Battistella M, Vergier B, Bailly JY, Cogrel O, et al. Clinical factors predictive for histological aggressiveness of basal cell carcinoma: A prospective study of 2274 cases. Ann Dermatol Venereol. 2019;S0151-9638:31014-2.

15. Xie P, Lefrançois P. Efficacy, safety, and comparison of sonic hedgehog inhibitors in basal cell carcinomas: A systematic review and meta-analysis. J Am Acad Dermatol. 2018;79:1089-1100.e17. 


\section{www.odermatol.com}

16. Newlands C, Currie R, Memon A, Whitaker S, Woolford T. Nonmelanoma skin cancer: United Kingdom National Multidisciplinary Guidelines. J Laryngol Otol. 2016;130:S125-32.

17. Lohuis PJ, Joshi A, Borggreven PA, Vermeeren L, Zupan-Kajcovski B, Al-Mamgani A, et al. Aggressive basal cell carcinoma of the head and neck: Challenges in surgical management. Eur Arch Otorhinolaryngol. 2016;273:3881-9.

18. Guinot JL, Rembielak A, Perez-Calatayud J, Rodríguez-Villalba S, Skowronek J, Tagliaferri L, et al. GEC-ESTRO ACROP recommendations in skin brachytherapy. Radiother Oncol. 2018;126:377-85.

19. Frakulli R, Galuppi A, Cammelli S, Macchia G, Cima S,
Gambacorta MA, et al. Brachytherapy in non melanoma skin cancer of eyelid: a systematic review. J Contemp Brachytherapy. 2015;7:497-502.

20. Tanese K. Diagnosis and management of basal cell carcinoma. Curr Treat Options Oncol. 2019;20:13.

Copyright by Sara Elloudi, et al. This is an open access article distributed under the terms of the Creative Commons Attribution License, which permits unrestricted use, distribution, and reproduction in any medium, provided the original author and source are credited.

Source of Support: Nil, Conflict of Interest: None declared. 